Research Article

\title{
Simultaneous Quantification of Four Ginsenosides in Rat Plasma and Its Application to a Comparative Pharmacokinetic Study in Normal and Depression Rats Using UHPLC-MS/MS
}

\author{
Lian-yun Du $\mathbb{D}^{1},{ }^{1}$ Tao Jiang $\mathbb{D}^{1},{ }^{1}$ Kun Wei $\mathbb{D},{ }^{2}$ Shuang Zhu $\mathbb{D},{ }^{1}$ Yan-long Shen $\mathbb{D}^{1},{ }^{1}$ Ping Ye $\mathbb{D}^{1},{ }^{1}$ \\ Hui-e Zhang $\mathbb{D}^{1},{ }^{1}$ Chang-bao Chen $\mathbb{D}^{1},{ }^{1}$ and En-peng Wang $\mathbb{D}^{1}$ \\ ${ }^{1}$ Jilin Ginseng Academy, Changchun University of Chinese Medicine, Changchun 130117, Jilin, China \\ ${ }^{2}$ Affiliated Hospital of Changchun University of Chinese Medicine, Changchun University of Chinese Medicine, \\ Changchun 130117, Jilin, China
}

Correspondence should be addressed to Chang-bao Chen; chencb@ccucm.edu.cn and En-peng Wang; wangep@ccucm.edu.cn Received 25 June 2021; Accepted 14 August 2021; Published 25 August 2021

Academic Editor: Antony C. Calokerinos

Copyright (c) 2021 Lian-yun Du et al. This is an open access article distributed under the Creative Commons Attribution License, which permits unrestricted use, distribution, and reproduction in any medium, provided the original work is properly cited.

A sensitive method has been developed for simultaneous determination of ginsenoside $R h_{1}\left(G-R h_{1}\right)$, ginsenoside $R b_{1}\left(G-R b_{1}\right)$, ginsenoside $\mathrm{Rc}(\mathrm{G}-\mathrm{Rc})$, and ginsenoside $\mathrm{Rd}(\mathrm{G}-\mathrm{Rd})$ in rat plasma of normal and depression model group after oral administration of their solutions by using Ultra-High-Performance Liquid Chromatography-Tandem Mass Spectrometry (UHPLC-QQQ-MS). The biological samples were prepared by protein precipitation. Ginsenoside $\operatorname{Rg}_{3}\left(G-\mathrm{Rg}_{3}\right)$ was used as an internal standard (IS). MS analysis was performed under the multiple reaction monitoring (MRM) with electron spray ionization (ESI) operated in the negative mode. The method showed good linearity over a wide concentration range $\left(R^{2}>0.999\right)$ and obtained lower limits of quantification (LLOQ) of $5 \mathrm{ng} / \mathrm{mL}$. The whole analysis procedure could be completed in as short as 16.5 min. The intraday precisions, interday precisions, and stabilities were less than $10 \%$. The extraction recoveries from rat plasma were exceeded $86.0 \%$. The results indicated that there were significant differences between the two groups on pharmacokinetics parameters; the absorptions of four analytes in the depression group were higher than those in the normal group because the liver metabolism and internal environment of the model rats had been affected.

\section{Introduction}

Depression is a sort of chronic mental disorder characterized by persistent black mood, which seriously affects the physical and mental health of human race [1]. Up to now, a large number of studies illustrated that a certain relationship was observed between the incidence of depression and the maladjustment of Hypothalamus-Pituitary-Adrenal (HPA), and excessive stress stimulation was considered to be the major cause of depression occurrence [2-5]. A natural stressful stimulus such as UVB radiation can trigger the activation of the HPA axis [6], no matter what acute or chronic dose irradiation may both individually reduce neurogenesis and synaptic protein expression, which finally lead to a depression-like behavior $[7,8]$.
At present, conventional chemical medicines on depression usually have various limitations or side effects, such as sleep disorders, cognitive dysfunction, high recurrence rate, and even much more severe effects [9-11]. Sometimes, as a complementary and alternative way, we often turn our eyes toward the traditional medicine (TM). TM has the advantages of much fewer side effects and lower toxicity, as well as higher efficacy and plenty of cured cases in the area of depression [12]. Ginseng, one of the most popular plants in East Asia, Europe, and North America, enjoys its reputation of "The king of herbs" [13-15]. Ginsenosides, widely considered as the main active ingredients, show a variety of pharmacological activities including increasing the ability to resist pressure, stimulating immune function, and protecting the nervous system and were responsible for the anti- 
inflammation function, antioxidation, and immunomodulatory effect $[16,17]$. Lately, some up-to-date studies have demonstrated that ginseng has a huge potential in antidepression treatment procedures, and many active ingredients from the herb have a chance to be the candidate drugs [18-20]. It has been proved that some PPD-type ginsenosides including $G-\mathrm{Rb}_{1}, \mathrm{G}-\mathrm{Rd}$, and partial PPT-type ginsenosides have antidepressant and neuroregulatory effects and other PPD-type ginsenoside such as G-Rc may participate in the regulation of neuroprotection [21-25].

UHPLC-MS/MS has been widely focused on the preclinical analytical application research and pharmacokinetics during the last decade [26]. Small particle sizes in columns in UHPLC systems play a crucial role in the process of separation, which can not only increase separation efficiency and sensitivities but also reduce the chromatographic run time [27]. Thus, the purpose of this article was to set up a sensitive, selective, and accurate method to simultaneously performing the quantitation analysis on $\mathrm{G}-\mathrm{Rh}_{1}, \mathrm{G}-\mathrm{Rb_{1 }}$, G-Rc, and G-Rd in rat plasma. It was expected to reveal how depression affects the absorption and metabolism on those active substances mentioned above through the pharmacokinetic parameter comparison between normal and depressed rats. It was expected that the results of this study will provide a broader idea for future antidepression studies on ginseng and the simultaneous determination methodology via mass spectrometry on ginsenosides.

\section{Materials and Methods}

2.1. Chemicals, Reagents, and Animals. G-Rh ${ }_{1}, \mathrm{G}-\mathrm{Rb}_{1}, \mathrm{G}-\mathrm{Rc}$, G-Rd, and G-Rg (purity $>99 \%$ ) were purchased from the National Institute for the Control of Pharmaceutical and Biological Products (Beijing, China). HPLC-grade methanol and acetonitrile were purchased from Fisher Scientific (Waltham, Massachusetts, USA). All other chemicals in the experiment were analytical grade. The water $(18.2 \mathrm{M})$ used in the experiment was doubly distilled water, and it was obtained from a laboratory water purification system $(\mathrm{HHi}-$ tech, China).

48 male Wistar rats (6 8 weeks old, $180 \pm 20 \mathrm{~g})$ were purchased from Liaoning Changsheng Biotechnology Co., Ltd. (Benxi, China), and their certification number was 2631260011107325. Rats were housed in a squirrel cage in a house with a temperature of $22 \pm 2{ }^{\circ} \mathrm{C}$ and relative humidity of $50 \% \pm 2 \%$. All animals received food and water ad libitum. The animals were acclimatized to the house for 3 days prior to the experiment. All the experimental procedures were performed according to the Guide for the Care and Use of Laboratory Animals and related ethics regulations of Changchun University of Chinese Medicine.

After 3 days of acclimatization in facilities, 48 rats were randomly divided into two groups with 24 rats in each group: one group was the normal group, and the other group was the depression model group. The normal group did not undergo any treatment during the modeling process, the depression model group was induced by ultraviolet radiation $B$ (UVB). The shaved back of the Wister model rat was $30 \sim 42 \mathrm{~cm}$ from the light source and exposed to $366 \mathrm{~mJ} \cdot \mathrm{cm}^{-2}$ of UVB for 5 days in a homemade box. After the 6th day, the animals were irradiated once for 2 days for a total of 22 days (14 times). The total radiation dose was $5.12 \mathrm{~J} \cdot \mathrm{cm}^{-2}$. After the successful establishment of the model, the normal group and the depression model group were randomly divided into four groups, respectively. Four groups of rats in the normal group were taken orally with different analytes, respectively, including oral administration of $\mathrm{G}-\mathrm{Rh}_{1}, \mathrm{G}-\mathrm{R} \mathrm{b}_{1}, \mathrm{G}-\mathrm{Rc}$, and G-Rd, same for the depression model group.

2.2. Instruments and UHPLC-MS/MS Conditions. The UHPLC-MS/MS system consisted of a Thermo Ultimate 3000 system and TSQ ENDURA mass spectrometer using an electrospray ionization (ESI) and X Calibur data processing system (Thermo, USA). Optimized MS parameters were as follows: drying gas temperature, $350^{\circ} \mathrm{C}$; ion transport tube temperature, $325^{\circ} \mathrm{C}$; gasification temperature, $275^{\circ} \mathrm{C}$; atomizing gas pressure, $255 \mathrm{kPa}$; sheath gas, $35 \mathrm{psi}$; aux gas, 10 psi; sweep gas, 2 psi; collision voltage, $3500 \mathrm{~V}$; the cracking voltage, $175 \mathrm{~V}$; and the tapered voltage, $65 \mathrm{~V}$. The injection volume was $5 \mu \mathrm{L}$, and the total run time was $16.5 \mathrm{~min}$. Some parameters of MRM are shown in Table 1.

The mass spectrometer was operated by the negative multiple reaction monitoring (MRM) mode. Chromatography was achieved on an Ascentis ${ }^{\circledR}$ Express $\mathrm{C}_{18}$ column $(5.0 \mathrm{~mm} \times 3.0 \mathrm{~mm}, 2.7 \mu \mathrm{m})$ from Sigma-Aldrich (St. Louis, MO, USA). The gradient elution mobile phase was composed of $0.1 \%$ formic acid-purified water in phase $\mathrm{A}$ and acetonitrile in phase $\mathrm{B}$. The gradient program was as follows: 0 2 $\mathrm{min}, 20 \% \mathrm{~B} ; 2 \sim 5 \mathrm{~min}, 20 \% \mathrm{~B} \longrightarrow 35 \% \mathrm{~B} ; 5 \sim 10 \mathrm{~min}, 35 \%$ $\mathrm{B} \longrightarrow 41 \% \mathrm{~B} ; 10 \sim 13 \mathrm{~min}, 41 \% \mathrm{~B} \longrightarrow 80 \% \mathrm{~B} ; 13 \sim 14 \mathrm{~min}, 80 \%$ $\mathrm{B} \longrightarrow 20 \% \mathrm{~B}$; and $14 \sim 16.5 \mathrm{~min}, 20 \% \mathrm{~B}$. The flow rate was set at $0.3 \mathrm{~mL} / \mathrm{min}$, and the temperature was kept at $35^{\circ} \mathrm{C}$.

\subsection{Behavior Testing}

2.3.1. Sucrose Preference Test. In order to see if the rats were prone to depression, the sucrose preference test was applied. We referred to the method in [28] and improved it appropriately. Before starting the test, rats were kept in quiet rooms and adapted to the sucrose solution. First, we prepared two bottles of $1 \%$ sucrose solution for rats to drink for $24 \mathrm{~h}$, followed by one bottle of $1 \%$ sucrose solution and one bottle of pure water for $24 \mathrm{~h}$, and changed the positions of the two bottles at the intermediate point of time. Rats were banned drinking water for $24 \mathrm{~h}$, and their preference was tested for sucrose solution. In this experiment, all rats were kept in a single cage for $24 \mathrm{~h}$ and prepared with two bottles of water which were weighed before the experiment, and the amount of sucrose solution the rats drank was calculated by the difference between weight before and after the test. The sucrose preference was calculated as follows: sucrose preference $(\%)=$ sucrose consumption $(\mathrm{g}) /$ (sucrose consumption $(\mathrm{g})+$ pure water consumption $(\mathrm{g})) \times 100 \%$.

2.3.2. Forced Swimming Test. Each rat was placed into a cylindrical container; the container was $11 \mathrm{~cm}$ in diameter, 
TABLE 1: Optimized parameters for the detection of $\mathrm{G}-\mathrm{Rh}_{1}, \mathrm{G}-\mathrm{R} \mathrm{b}_{1}, \mathrm{G}-\mathrm{Rc}, \mathrm{G}-\mathrm{Rd}$, and IS.

\begin{tabular}{|c|c|c|c|c|c|c|c|}
\hline Analytes & Retention time (min) & Detect mode & Precursor & Product & Collision energy $(\mathrm{eV})$ & RF lens $(\mathrm{V})$ & Fragmentor voltage $(\mathrm{V})$ \\
\hline $\mathrm{G}-\mathrm{Rh}_{1}$ & 4.75 & ESI & 637.3583 & $\begin{array}{l}475.5166 \\
945.5067\end{array}$ & 40.287 & 198.371 & 175 \\
\hline $\mathrm{G}-\mathrm{Rb}_{1}$ & 8.70 & ESI & 1107.5560 & $\begin{array}{l}783.4598 \\
621.4125\end{array}$ & 55.000 & 259.652 & 220 \\
\hline G-Rc & 10.14 & ESI & 1077.5464 & $\begin{array}{l}945.4226 \\
783.4203 \\
621.2607 \\
459.5873 \\
783.8463\end{array}$ & 49.792 & 247.820 & 175 \\
\hline G-Rd & 12.51 & ESI & 945.4976 & $\begin{array}{l}621.5194 \\
459.2995\end{array}$ & 45.646 & 276.337 & 220 \\
\hline $\mathrm{G}-\mathrm{Rg}_{3}$ (IS) & 13.28 & ESI & 783.4890 & $\begin{array}{l}621.4325 \\
459.3777 \\
\end{array}$ & 41.449 & 298.483 & 175 \\
\hline
\end{tabular}

$25 \mathrm{~cm}$ in height, and $20 \mathrm{~cm}$ in the depth of the water $(25 \pm 1$ $\left.{ }^{\circ} \mathrm{C}\right)$. The test duration was $6 \mathrm{~min}$, and the time of the experiment was recorded by two trained students [29]. The rat was quiescent, and the body did not struggle as a standard of immobility. After the experiment, the rats were dried with a towel.

2.3.3. Open-Field Test. This test is intended to test if the animals exhibit a depression-like behavior, using a square box $(100 \times 72 \times 40 \mathrm{~cm})$ and a mobile phone. Rats were put in the center of the box, respectively, followed by mobile phone shooting and timekeeping at the same time, which stopped after $5 \mathrm{~min}$. The number of horizontal movements and the number of vertical movements were recorded by using the mobile phone, respectively [29]. After testing each rat, the inside and bottom of the box were thoroughly cleaned with alcohol so as not to affect the next test result.

2.4. Preparation of Stocks, Calibration Samples, and Quality Control Samples. The stock solutions of $\mathrm{G}-\mathrm{Rh}_{1}, \mathrm{G}-\mathrm{Rb}_{1}$, G-Rc, G-Rd, and IS were prepared separately in methanol at the final concentration of $1.0,1.0,1.0,1.0 \mathrm{mg} \cdot \mathrm{mL}^{-1}$, and $1.5 \mu \mathrm{g} / \mathrm{mL}$, respectively, and then, the standard working solutions were prepared by the stock solutions which were diluted with methanol. The IS working solution was also prepared by diluting the IS stock solution with methanol. The calibration curve standard samples were prepared by spiking $100 \mu \mathrm{L}$ of the working solution into $100 \mu \mathrm{L}$ of rat blank plasma at final concentrations of $5-10000 \mathrm{ng} \cdot \mathrm{mL}^{-1}$ of $\mathrm{G}-\mathrm{Rh}_{1}, \mathrm{G}-\mathrm{Rb}_{1}, \mathrm{G}-\mathrm{Rc}$, and G-Rd. Then, each sample was spiked with $100 \mu \mathrm{L}$ of the IS solution and $100 \mu \mathrm{L}$ of the methanol solution, vortexed for $3 \mathrm{~min}$, and centrifuged at $12000 \mathrm{r} / \mathrm{min}$ for $10 \mathrm{~min}$. Finally, the supernatant was filtered through a $0.22 \mu \mathrm{m}$ microporous membrane and all the solutions were stored at $4^{\circ} \mathrm{C}$ before analysis. The blank control was prepared with $100 \mu \mathrm{L}$ rat blank plasma, and then, the abovementioned steps were completed. Three levels $(25,250$, and $2500 \mathrm{ng} / \mathrm{mL}$ ) of quality control (QC) samples were prepared by spiking standard working solutions into blank plasma.
2.5. Sample Preparation. All the plasma samples were stored at $-20^{\circ} \mathrm{C}$ and thawed at room temperature immediately before the experiment. Each plasma sample $(100 \mu \mathrm{L})$ was added to a $1.5 \mathrm{~mL}$ tube and then proceeded as per the method under Section 2.4.

2.6. Method Validation. According to the Food and Drug Administration guidelines, we validated the established method.

2.6.1. Specificity. In order to verify the specificity of the method, we compared the chromatograms of rat blank plasma, rat blank plasma spiked with four analytes and IS and rat plasma sample $1 \mathrm{~h}$ after administration of four analytes at a dose of $80 \mathrm{mg} / \mathrm{kg}$.

2.6.2. The Linearity of Calibration Curves. The linearity of the assay for rat plasma was assessed by analyzing the calibration curves using least-squares linear regression of the peak area ratios of the analyte to the IS versus the nominal concentration of the calibration standard with a weighed factor $\left(1 / x^{2}\right)$. The minimum concentration of the standard curve was taken as the lower limit of quantification (LLOQ).

2.6.3. Intraday Precision, Interday Precision, and Accuracy. In order to evaluate the intraday precision, interday precision, and accuracy, we analyzed three concentration levels $(25,250$, and $2500 \mathrm{ng} / \mathrm{mL})$ of the QC plasma samples with six replicates at the same day and 3 continuous days, respectively, with the relative standard deviation (RSD) for precision and relative error (RE) standards for accuracy.

2.6.4. Recovery and Matrix Effect. In order to evaluate the recoveries of $\mathrm{G}-\mathrm{Rb}_{1}, \mathrm{G}-\mathrm{Rc}, \mathrm{G}-\mathrm{Rd}$, and $\mathrm{G}-\mathrm{Rh}_{1}$, we compared the peak area of QC $(25,250$, and $2500 \mathrm{ng} / \mathrm{mL})$ samples with the corresponding concentration spiked into the blank plasma sample. In order to evaluate the matrix effects, we compared the peak areas of QC samples with the areas of the corresponding concentration standard solutions. IS was determined in the same manner. 
2.6.5. Stability. For confirming the stability of four analytes, we analyzed QC samples with three replicates under the following conditions: stability of short term (samples stored at room temperature for $24 \mathrm{~h}$ ); stability of long term (samples stored at $-20^{\circ} \mathrm{C}$ for 15 days); and stability of freeze/ thaw $\left(3\right.$ cycles, $-20^{\circ} \mathrm{C}$, room temperature).

\subsection{Method Application}

2.7.1. Pharmacokinetic Study. 24 rats of the model group were induced into the depressive model by the previously described method. The animals were fasted for $12 \mathrm{~h}$ with free access to water prior to the experiment; then, the normal and depression model group of rats were assigned to receive $\mathrm{G}-\mathrm{Rh}_{1}, \mathrm{G}-\mathrm{Rb}_{1}, \mathrm{G}-\mathrm{Rc}$, and G-Rd by oral administration of their solutions (suspended in 0.5\% CMC-NA), respectively. In addition, $80 \mathrm{mg} / \mathrm{kg}$ was selected as the oral administration dose according to the previous laboratory studies and the requirements of experiments [30]. Blood samples (about $250 \mu \mathrm{L}$ ) were obtained via the rats' orbital vein at $0.08,0.17$, $0.33,0.5,1.0,2.0,4.0,6.0,8.0,12,24,36,48$, and $72 \mathrm{~h}$ after oral administration and were collected into heparinized centrifuge tubes. The blood samples were cooled naturally for 30 minutes and centrifuged at $3000-r / m i n$ for $10 \mathrm{~min}$. The plasma samples obtained were stored at $-80^{\circ} \mathrm{C}$ until the experiment.

2.7.2. Pharmacokinetic Data Analysis. The pharmacokinetic parameters of four components obtained in this experiment are mainly as follows: area under the time concentration curve $\left(\mathrm{AUC}_{0-t}, \mathrm{AUC}_{0-\infty}\right)$, the peak concentration $\left(C_{\max }\right)$, mean residence time $(\mathrm{MRT})$, elimination half-life $\left(T_{1 / 2}\right)$, the peak time $\left(T_{\max }\right)$, clearance rate $(\mathrm{CLz} / \mathrm{F})$, and so on. Twocompartmental analysis was used to calculate the relationship between the plasma concentration versus time data of four ginsenosides by using the DAS 3.0 software package (Chinese Pharmacological Society). Statistical analysis between the two groups was dealt with SPSS 21 using a OneWay ANOVA analysis. Data were expressed as mean $\pm \mathrm{SD}$, and the $p$ value less than 0.05 was considered to be significantly significant.

\section{Results and Discussion}

3.1. Rats Depression Model Was Successfully Established. In order to confirm whether the rat depression model was successfully established or not, we verified a series of indicators, such as the sucrose preference test, forced swimming test, and the open-field test. For the sucrose water consumption, there was no significant difference between the normal and the depression model group $(p>0.05)$ on day 0 (before stimulation). By contrast, the sucrose water consumption of the normal group was significantly higher than the depression group on the 22 nd day after treatments $(p<0.01)$. No significant difference was observed between the two groups during the forced swimming test, day 0 before the stimulation $(p>0.05)$, while the immobility time of the depression group was significantly longer than the normal group on the 22nd day after the beginning of the experiment $(p<0.05)$. It was shown no significant difference between groups on day 0 ( $p>0.05)$; however, the number of rearing of the depression group was significantly lower than the normal group by the end of the 22-day treatment periods in the open-field test $(p<0.01)$ (Figure 1). In conclusion, the establishment of the depressed model was successful.

3.2. Optimization of UHPLC-MS/MS Conditions. In order to obtain chromatographic analysis performance with better separation and retention time, two mobile phases, acetonitrile and methanol, were evaluated. The results showed that acetonitrile had better separation efficiency than methanol, which was more suitable for this experiment. $0.1 \%$ formic acid was added to the water as the mobile phase, and the chromatographic peak shape of IS and four analytes was more beautiful. Referring to the test, mass spectrometry analysis of IS and four analytes was performed using $0.1 \%$ formic acid-acetonitrile water as the mobile phase for the process of gradient elution. The results show that several ginsenosides are ionization in a negative ion mode, and the mass spectrum of five ginsenosides is shown in Figure 2.

\subsection{Method Validation}

3.3.1. Specificity. As shown in Figure 3, it was observed that the retention time of endogenous did not interfere with the determination of the four analytes and the internal standard. The method showed good selectivity and baseline separation. The retention time was $4.75 \mathrm{~min}, 8.70 \mathrm{~min}, 10.14 \mathrm{~min}$, $12.51 \mathrm{~min}$, and $13.28 \mathrm{~min}$, respectively.

3.3.2. The Linearity of Calibration Curves. The linear relationship of the calibration curve was established by plotting the relationship between peak area ratios and the concentration of the four analytes. The four analytes exhibited good linearity with correlation coefficients $\left(R^{2}>0.999\right)$. The LLOQ of the four analytes was lower than $5 \mathrm{ng} / \mathrm{mL}, 5 \mathrm{ng} / \mathrm{mL}$, $5 \mathrm{ng} / \mathrm{mL}$, and $5 \mathrm{ng} / \mathrm{mL}$, respectively, which met the quantitative requirements (Table 2 ).

3.3.3. Intraday Precision, Interday Precision, and Accuracy. Table 3 indicated the precision and accuracy of the method. The results presented that the precisions and accuracies of all the four analytes are good and acceptable (RSD $\leq 9.69 \%$, $-8.92 \% \leq \mathrm{RE} \leq 7.70 \%)$.

3.3.4. Recovery and Matrix Effect. As shown in Table 3, the recoveries of four analytes at three concentrations were $86.06 \% \sim 96.86 \%$ and the matrix effects of them were $87.37 \% \sim 97.57$. Meanwhile, the recoveries and the matrix effects of IS were $93.76 \pm 3.28 \%$ and $95.12 \pm 2.90 \%$, indicating that the method was satisfactory.

3.3.5. Stability. As shown in Table 4, the RE and RSD values of four analytes range from -9.34 to 8.15 , and it can be seen 

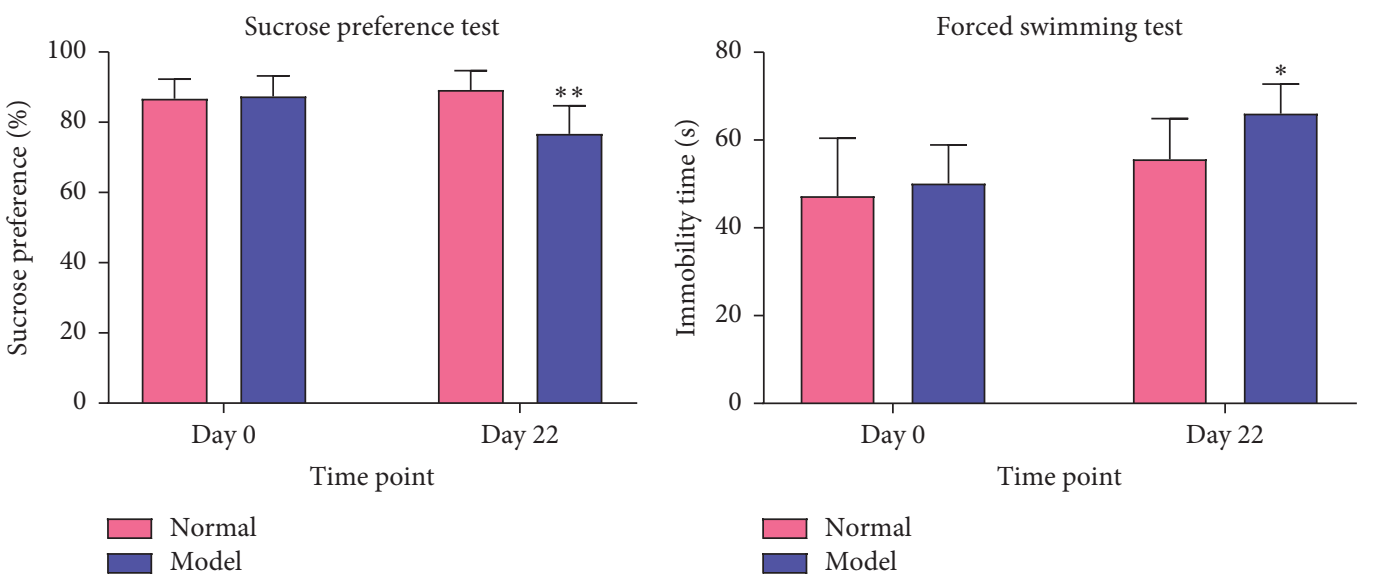

(a)

(b)

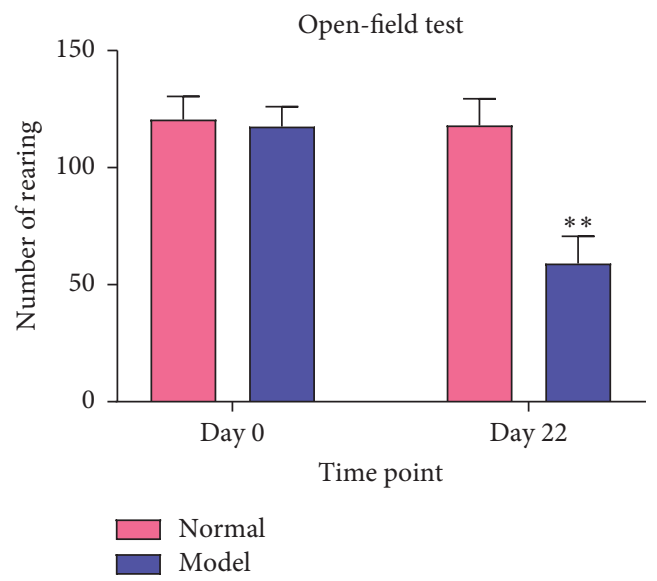

(c)

Figure 1: The successful construction of the rat depression model: the sucrose preference of rats in the sucrose preference test (a); the immobility time of rats in the forced swimming test (b); the number of rearing of rats in the Open-field test (c). The values were expressed as the mean \pm SD for $n=6 .{ }^{*} p<0.05,{ }^{* *} p<0.01$.

from the abovementioned results that four analytes in plasma remained stable under different storage conditions, and the results met the requirements of this experiment.

3.4. Pharmacokinetic Application and Discussion. In this study, it was verified that the UHPLC-MS/MS method had been successfully applied to the quantitative analysis in rat plasma after oral administration of $\mathrm{G}-\mathrm{Rh}_{1}, \mathrm{G}-\mathrm{Rb}_{1}, \mathrm{G}-\mathrm{Rc}$, and G-Rd solutions to individual rats $(n=6)$ in the normal and depressed model. According to the F-test and Akaike's information criterion, a two-compartment PK model fitted the plasma data of the ginsenosides in the normal and depression model group of rats. The calculated $\mathrm{PK}$ parameters were $C_{\text {max }}, T_{\max }, \mathrm{AUC}_{0-t}, \mathrm{AUC}_{0-\infty}, T_{1 / 2}, \mathrm{CLz} / \mathrm{F}$, and MRT, and they are summarized in Table 5 . The mean plasma concentration-time curve is presented in Figure 4.

According to the pharmacokinetic data between the two groups of rats, as Table 5 shows, $C_{\max }$ of $\mathrm{G}-\mathrm{Rh}_{1}, \mathrm{G}-\mathrm{Rb} \mathrm{b}_{1}$, and G-Rc increased remarkably compared with the normal group $(p<0.05)$, while the G-Rd concentration increased but not significantly. AUC had a similar phenomenon,
$\mathrm{G}-\mathrm{Rh}_{1}, \mathrm{G}-\mathrm{Rb}_{1}$, and G-Rd increased significantly, but G-Rc was not. In a word, we could easily find that the AUC values and $C_{\max }$ values in the depression model group were increased and $\mathrm{Clz} / \mathrm{F}$ was decreased as compared with the normal group, and the bioavailability of ginsenosides in the depression model could be improved. Liver metabolism can be influenced by a variety of external factors, including typical psychosocial factors such as depression [31]. The depression induced by UVB radiation was able to change the internal environment of rats by producing oxidative damage to hepatocytes which subsequently affect their normal metabolism in the liver [32-34]. However, the activities of CYP450 enzymes in liver microsomal can be enhanced by UVB-induced depression in the previous report. As a result, it can be easily speculated that the increased blood concentration of four ginsenosides may have some connection with inhibiting the activities of CYP450 enzymes to show their potential efficacy of antidepressant effect [32]. Among the four analytes, G-Rb showed the largest value of AUC, and previous studies reported the potential efficiency of the antidepressant of $\mathrm{G}-\mathrm{Rb}_{1}$ [35]. Also, it had been reported that both $\mathrm{G}-\mathrm{Rb}_{1}$ and 


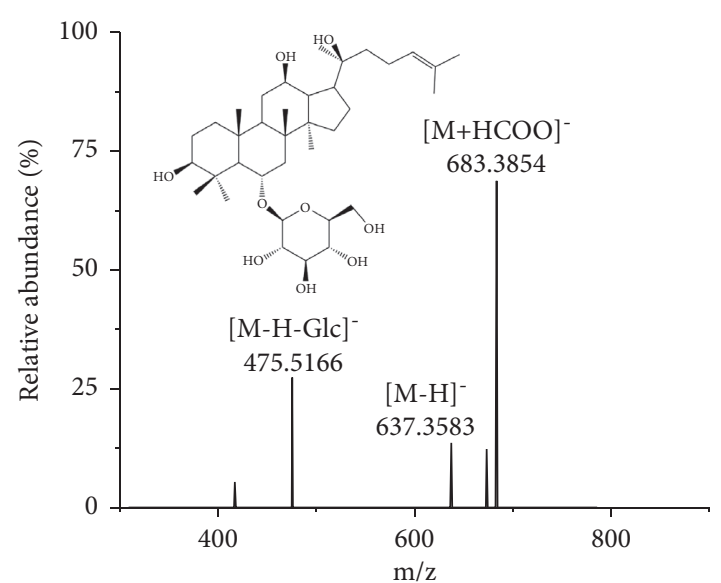

(a)

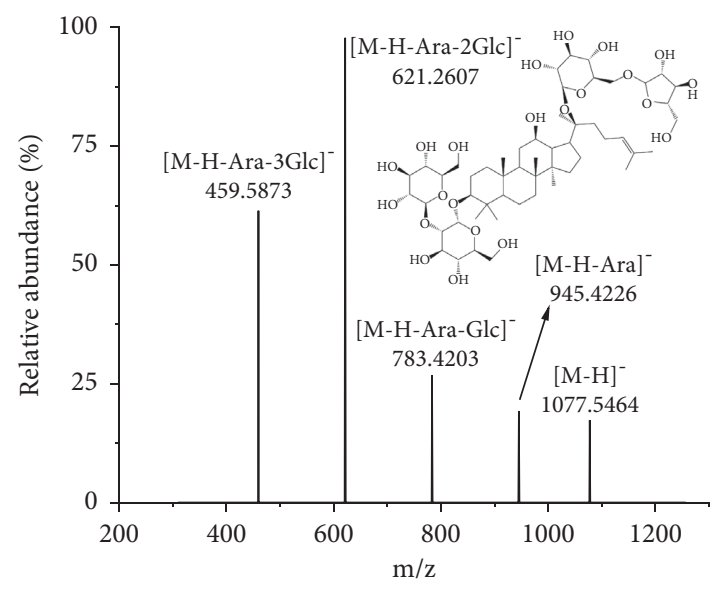

(c)

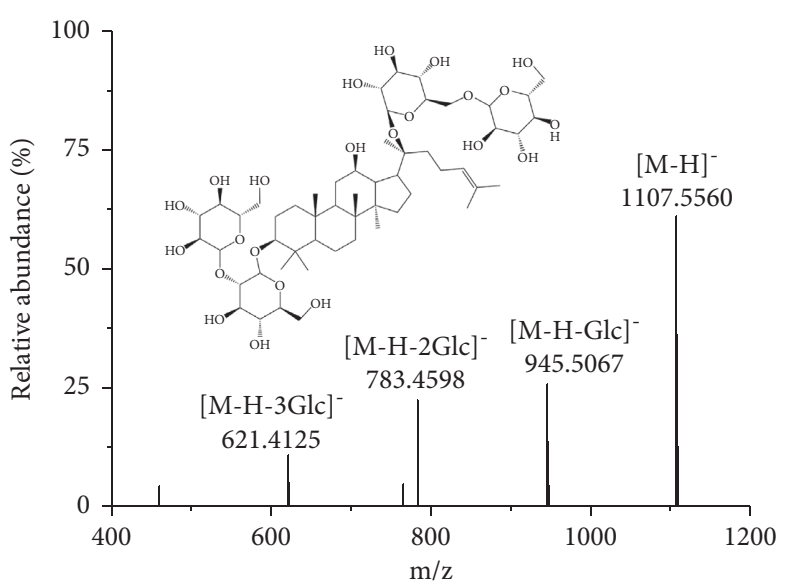

(b)

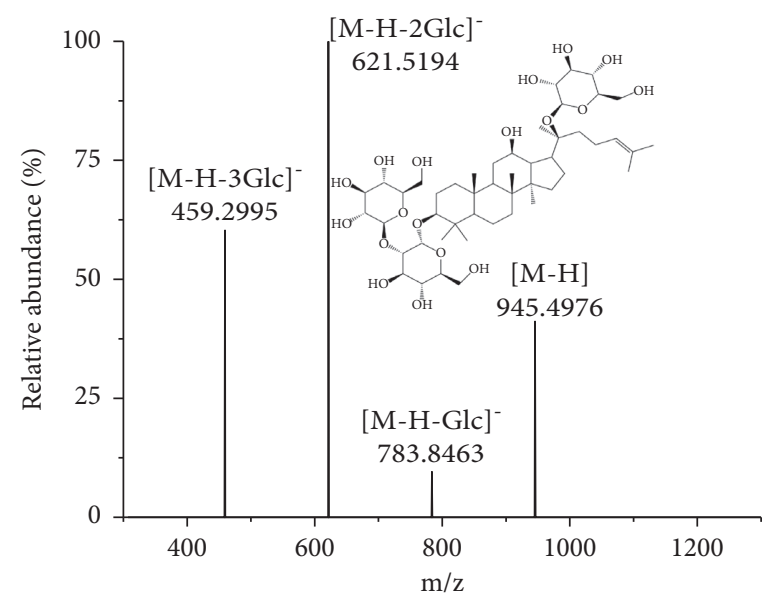

(d)

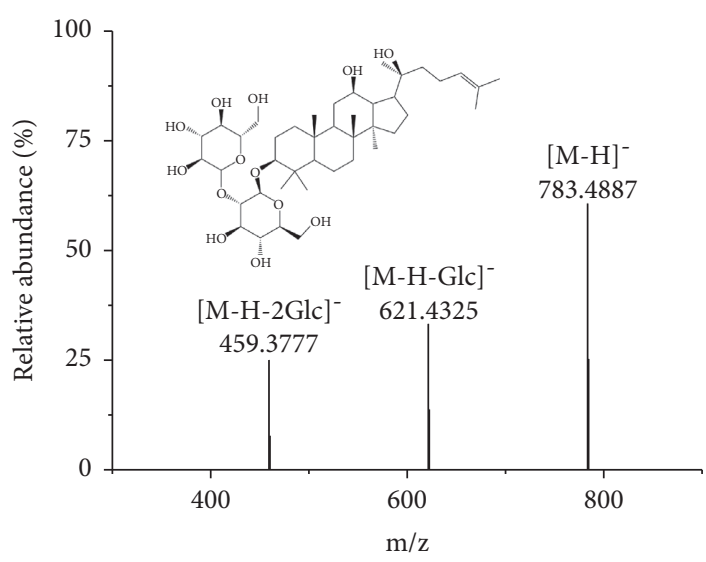

(e)

Figure 2: Chemical structures and product ions of G-Rh1 (a), G-Rb1 (b), G-Rc (c), G-Rd (d), and IS (e).

G-Rc can improve the activities of total glutathione (GSH) and superoxide dismutase (SOD) activities in cells after UVB irradiation $[36,37]$. In the previous study, it had been found that oral administration of G-Rd could significantly alleviate depression by stimulating the NF- $\kappa \mathrm{B}-$ mediated BDNF expression in the hippocampus of rat [23]. G-Rh was rapidly absorbed in the rat plasma with an average Tmax of about $0.5 \mathrm{~h}$, while others reached their maximum plasma concentrations at the time point of about $1 \mathrm{~h}$. The differences between the two types could be ascribed to the widespread excretion of the PPD type in the renal and biliary tract more slowly than that of the PPT type [38]. 

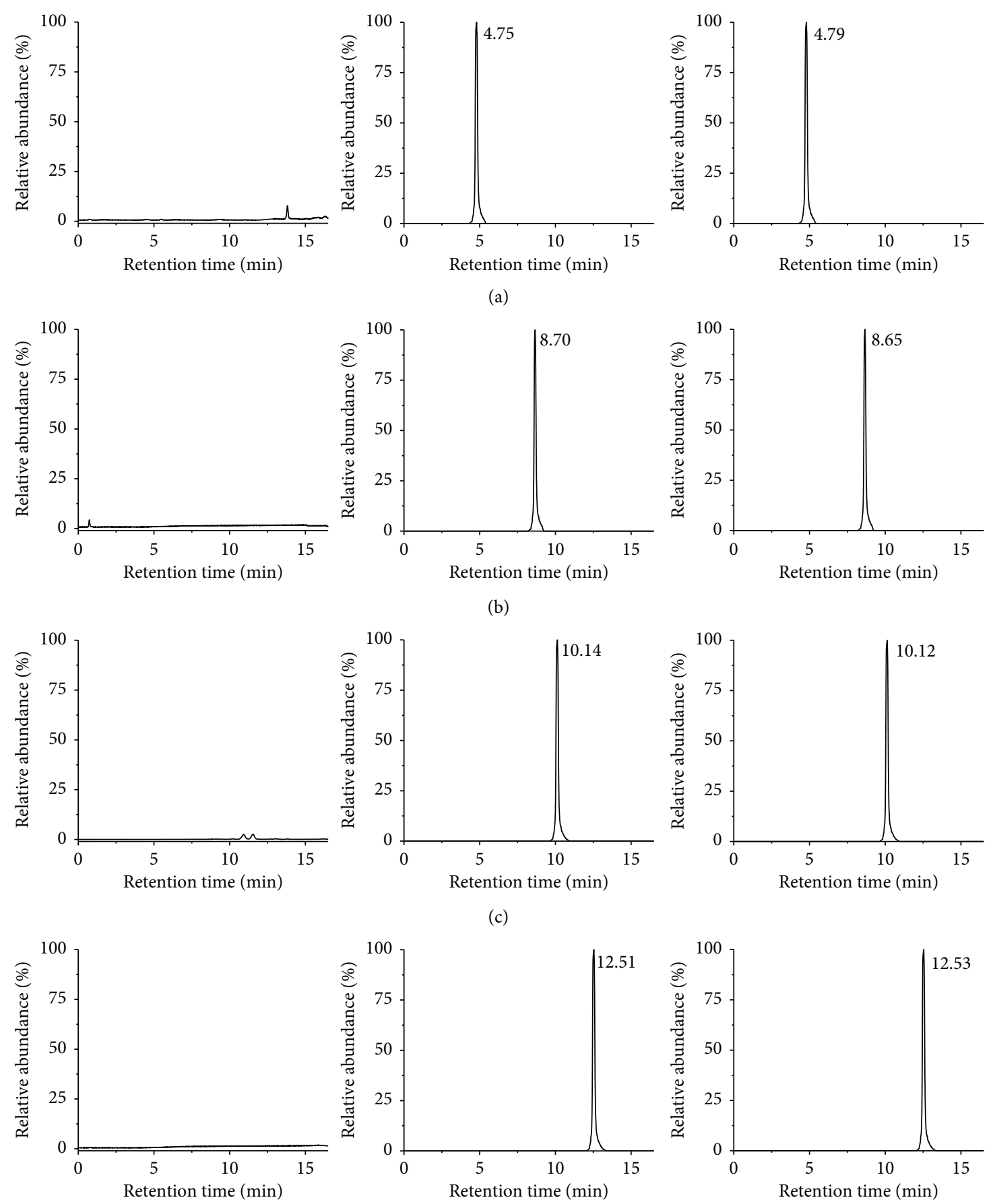

(c)
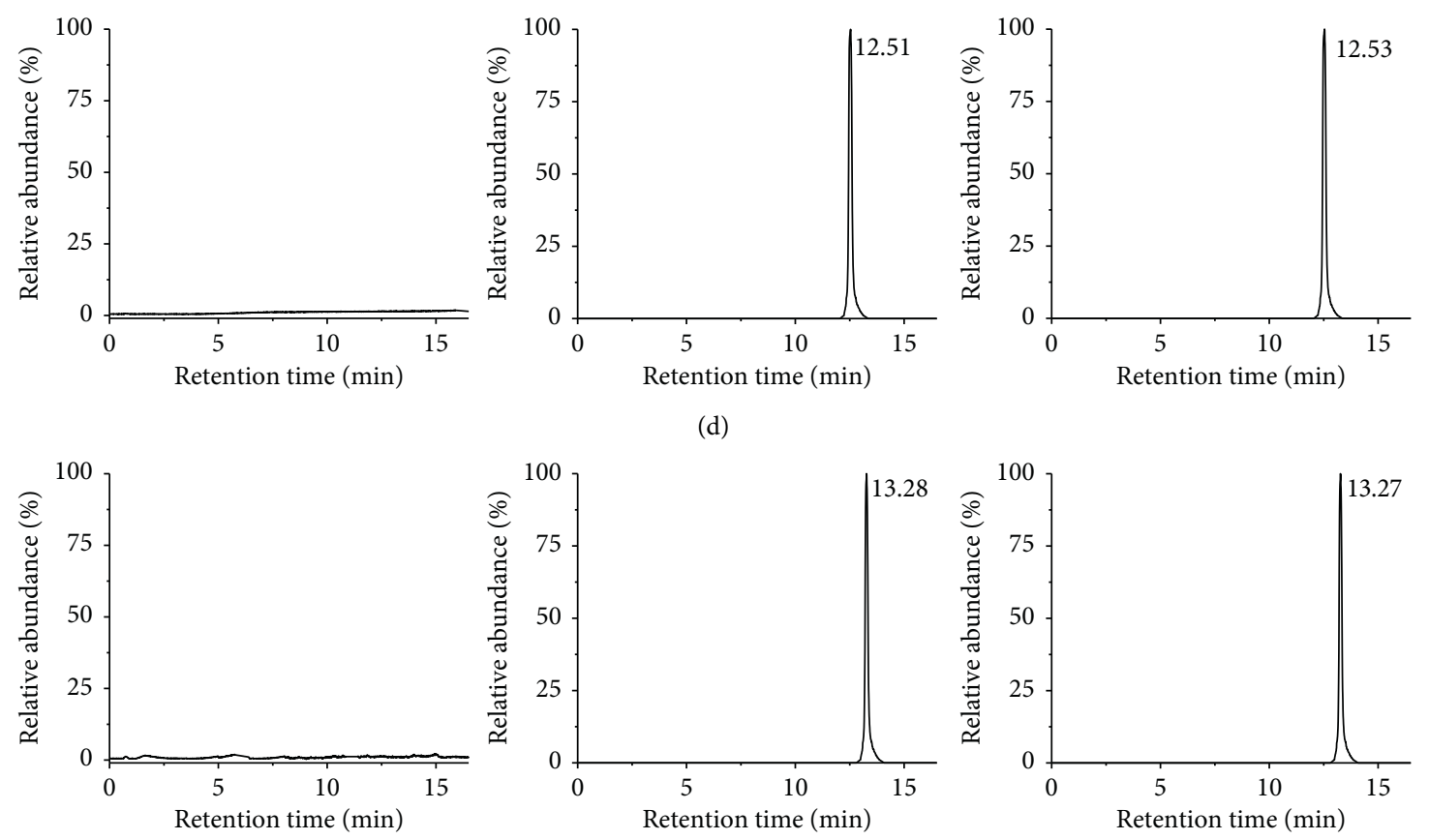

(e)

FIgURe 3: Representative multireaction monitoring mode chromatogram of G-Rh $(\mathrm{a}), \mathrm{G}-\mathrm{Rb} \mathrm{b}_{1}(\mathrm{~b}), \mathrm{G}-\mathrm{Rc}$ (c), G-Rd (d), and IS (e) in blank plasma (A), blank plasma spiked with four analytes and IS (B), and plasma sample $1 \mathrm{~h}$ after oral administration at a dose of $80 \mathrm{mg} / \mathrm{kg}(\mathrm{C})$. 
Table 2: The linearities for G-Rh $h_{1}, \mathrm{G}-\mathrm{Rb}_{1}, \mathrm{G}-\mathrm{Rc}$, and G-Rd $(n=3)$.

\begin{tabular}{|c|c|c|c|c|c|}
\hline Analytes & Calibration curves & Linear range $(\mathrm{ng} / \mathrm{mL})$ & $R 2$ & LLOD (ng/mL) & LLOQ (ng/mL) \\
\hline G-Rh1 & $y=0.0006 x+0.0015$ & $5-10000$ & 0.9997 & 1.5 & 5 \\
\hline G-Rb1 & $y=0.0001 x+0.0005$ & $5-10000$ & 0.9993 & 1.5 & 5 \\
\hline G-Rc & $y=0.0002 x+0.0010$ & $5-10000$ & 0.9999 & 1.5 & 5 \\
\hline G-Rd & $y=0.0005 x+0.0028$ & $5-10000$ & 0.9999 & 1.5 & 5 \\
\hline
\end{tabular}

TABLE 3: Summary of intraday and interday precisions, accuracies, extraction recoveries, and matrix effects of the four analytes in rat plasma $(n=6)$.

\begin{tabular}{lcccccc}
\hline Analytes & Concentration $(\mathrm{ng} / \mathrm{mL})$ & Intraday RSD (\%) & Interday RSD (\%) & Accuracy (RE\%) & Recovery (\%) & Matrix effect (\%) \\
\hline \multirow{3}{*}{$\mathrm{G}_{\mathrm{Rh}}$} & 25 & 9.43 & 9.69 & 0.58 & $90.65 \pm 2.34$ & $95.67 \pm 2.45$ \\
& 250 & 0.95 & 0.49 & 3.84 & $93.67 \pm 4.08$ & $87.37 \pm 8.45$ \\
& 2500 & 1.21 & 2.95 & 4.08 & $96.59 \pm 0.62$ & $97.57 \pm 3.11$ \\
\hline \multirow{3}{*}{$\mathrm{G}_{1}$} & 25 & 6.65 & 6.21 & -3.47 & $86.06 \pm 2.57$ & $91.33 \pm 0.96$ \\
& 250 & 0.98 & 4.56 & -1.44 & $91.86 \pm 2.25$ & $94.22 \pm 1.47$ \\
& 2500 & 3.50 & 2.38 & 2.38 & $94.19 \pm 1.55$ & $95.55 \pm 1.22$ \\
\hline $\mathrm{G}-\mathrm{Rc}$ & 25 & 5.35 & 6.21 & -7.44 & $89.46 \pm 5.13$ & $89.42 \pm 3.17$ \\
& 250 & 4.38 & 3.28 & 6.34 & $91.28 \pm 4.56$ & $94.43 \pm 5.85$ \\
& 2500 & 3.86 & 4.61 & -6.51 & $93.60 \pm 2.02$ & $96.85 \pm 7.33$ \\
\hline & 25 & 6.29 & 4.82 & -8.92 & $87.64 \pm 4.87$ & $91.78 \pm 5.38$ \\
$\mathrm{G}-\mathrm{Rd}$ & 250 & 1.65 & 2.20 & -5.12 & $90.87 \pm 0.56$ & $96.65 \pm 3.97$ \\
& 2500 & 3.87 & 4.51 & 7.70 & $96.86 \pm 5.08$ & $89.94 \pm 3.77$ \\
\hline
\end{tabular}

TABLE 4: Stabilities of G-Rh $, \mathrm{G}-\mathrm{Rb}_{1}, \mathrm{G}-\mathrm{Rc}$, and G-Rd under various storage conditions $(n=6)$.

\begin{tabular}{|c|c|c|c|c|c|c|c|c|c|}
\hline \multirow[t]{2}{*}{ Analytes } & \multirow[t]{2}{*}{ Concentration $(\mathrm{ng} / \mathrm{mL})$} & \multicolumn{2}{|c|}{$\begin{array}{l}\text { Short term }(24 \mathrm{~h}, \\
\text { room temperature })\end{array}$} & \multicolumn{2}{|c|}{$\begin{array}{c}\text { Long term (15 days, } \\
\left.-20^{\circ} \mathrm{C}\right)\end{array}$} & \multicolumn{2}{|c|}{$\begin{array}{c}\text { Freeze-thaw (3 } \\
\text { cycles) }\end{array}$} & \multicolumn{2}{|c|}{$\begin{array}{c}\text { Postpreparative ( } 8 \mathrm{~h} \text {, } \\
\left.4^{\circ} \mathrm{C}\right)\end{array}$} \\
\hline & & RE (\%) & RSD (\%) & RE (\%) & RSD (\%) & RE (\%) & RSD (\%) & $\mathrm{RE}(\%)$ & RSD (\%) \\
\hline \multirow{3}{*}{$\mathrm{G}-\mathrm{Rh}_{1}$} & 25 & 4.78 & 3.69 & -3.78 & 0.58 & 1.04 & 4.13 & 5.46 & 1.65 \\
\hline & 250 & -4.64 & 4.57 & -7.34 & 7.66 & 3.48 & 3.62 & 3.87 & 3.64 \\
\hline & 2500 & 3.75 & 2.56 & 6.66 & 5.93 & 4.86 & 0.78 & 5.19 & 4.79 \\
\hline \multirow{3}{*}{$\mathrm{G}-\mathrm{Rb}_{1}$} & 25 & 1.76 & 4.87 & 1.22 & 6.21 & 5.87 & 4.42 & 5.55 & 7.03 \\
\hline & 250 & -2.24 & 1.02 & 2.22 & 0.75 & -9.34 & 2.77 & 2.74 & 3.25 \\
\hline & 2500 & 2.08 & 3.62 & -3.06 & 4.24 & 3.98 & 2.95 & -7.34 & 1.58 \\
\hline \multirow{3}{*}{ G-Rc } & 25 & -3.43 & 4.02 & 4.43 & 4.89 & -6.43 & 4.93 & -4.39 & 5.63 \\
\hline & 250 & -6.34 & 4.38 & 6.32 & 7.36 & -5.65 & 4.7 & 4.53 & 1.07 \\
\hline & 2500 & 2.08 & 1.66 & 8.15 & 3.18 & 4.01 & 4.89 & 3.75 & 0.73 \\
\hline \multirow{3}{*}{ G-Rd } & 25 & 3.98 & 5.42 & 4.83 & 3.28 & 5.43 & 3.34 & -6.3 & 5.79 \\
\hline & 250 & -7.43 & 0.72 & -1.37 & 3.33 & -8.43 & 4.72 & 7.64 & 3.85 \\
\hline & 2500 & -3.87 & 2.09 & 2.65 & 3.23 & -1.75 & 4.05 & 3.85 & 0.17 \\
\hline
\end{tabular}

TABLE 5: Pharmacokinetic parameters of the four analytes in the normal and model group.

\begin{tabular}{|c|c|c|c|c|}
\hline Parameters & $\mathrm{G}-\mathrm{Rh}_{1}$ & $\mathrm{G}-\mathrm{Rb}_{1}$ & G-Rc & G-Rd \\
\hline \multicolumn{5}{|l|}{ Normal } \\
\hline$C_{\max }(\mathrm{mg} / \mathrm{L})$ & $15.163 \pm 0.815$ & $349.840 \pm 6.238$ & $7.741 \pm 0.366$ & $97.458 \pm 1.800$ \\
\hline$T_{\max }(\mathrm{h})$ & $0.50 \pm 0.01$ & $1.00 \pm 0.01$ & $1.00 \pm 0.01$ & $1.00 \pm 0.01$ \\
\hline $\operatorname{AUC}_{0-72}\left(\mathrm{mg} / \mathrm{L}^{*} \mathrm{~h}\right)$ & $128.871 \pm 68.509$ & $10399.870 \pm 5196.010$ & $228.760 \pm 110.731$ & $2061.658 \pm 1011.618$ \\
\hline $\operatorname{AUC}_{0-\infty}\left(\mathrm{mg} / \mathrm{L}^{*} \mathrm{~h}\right)$ & $129.100 \pm 68.507$ & $10585.975 \pm 5201.551$ & $229.541 \pm 110.102$ & $2062.555 \pm 1011.536$ \\
\hline$t_{1 / 2}(\mathrm{~h})$ & $10.731 \pm 0.905$ & $17.774 \pm 0.207$ & $9.659 \pm 1.093$ & $9.631 \pm 0.206$ \\
\hline $\mathrm{CLz} / \mathrm{F}(\mathrm{L} / \mathrm{h} / \mathrm{kg})$ & $621.227 \pm 54.664$ & $17.096 \pm 0.382$ & $647.808 \pm 36.107$ & $64.895 \pm 2.255$ \\
\hline MRT $(\mathrm{h})$ & $22.278 \pm 10.621$ & $15.952 \pm 0.851$ & $16.111 \pm 2.798$ & $13.997 \pm 0.390$ \\
\hline \multicolumn{5}{|l|}{ Model } \\
\hline$C_{\max }(\mathrm{mg} / \mathrm{L})$ & $20.010 \pm 1.027^{* *}$ & $385.694 \pm 8.339^{*}$ & $12.497 \pm 0.809^{* *}$ & $104.959 \pm 5.034$ \\
\hline$T_{\max }(\mathrm{h})$ & $0.50 \pm 0.01$ & $1.00 \pm 0.02$ & $1.00 \pm 0.01$ & $1.00 \pm 0.03$ \\
\hline $\operatorname{AUC}_{0-72}\left(\mathrm{mg} / \mathrm{L}^{*} \mathrm{~h}\right)$ & $148.939 \pm 62.329^{*}$ & $26347.000 \pm 13042.423^{*}$ & $295.337 \pm 165.908$ & $2583.439 \pm 1254.680^{*}$ \\
\hline $\operatorname{AUC}_{0-\infty}\left(\mathrm{mg} / \mathrm{L}^{*} \mathrm{~h}\right)$ & $149.172 \pm 62.330^{*}$ & $29419.304 \pm 12850.460^{*}$ & $295.641 \pm 166.081$ & $2587.285 \pm 1253.860^{*}$ \\
\hline$t_{1 / 2}(\mathrm{~h})$ & $9.765 \pm 0.825$ & $13.472 \pm 0.588^{* *}$ & $8.166 \pm 0.881$ & $10.198 \pm 0.511$ \\
\hline $\mathrm{CLz} / \mathrm{F}(\mathrm{L} / \mathrm{h} / \mathrm{kg})$ & $544.957 \pm 6.150$ & $11.994 \pm 0.385^{*}$ & $450.788 \pm 23.974$ & $55.744 \pm 2.366^{* *}$ \\
\hline $\operatorname{MRT}(\mathrm{h})$ & $16.589 \pm 1.745$ & $19.683 \pm 0.793^{*}$ & $14.639 \pm 0.190$ & $15.126 \pm 0.671$ \\
\hline
\end{tabular}

Data were reported as mean \pm SD for $n=6 .{ }^{*} p<0.05,{ }^{* *} p<0.01$, compared with the normal group. 


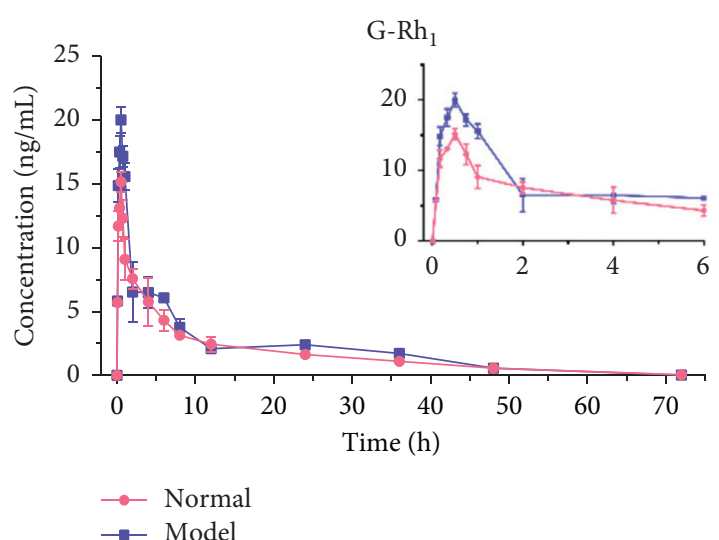

(a)

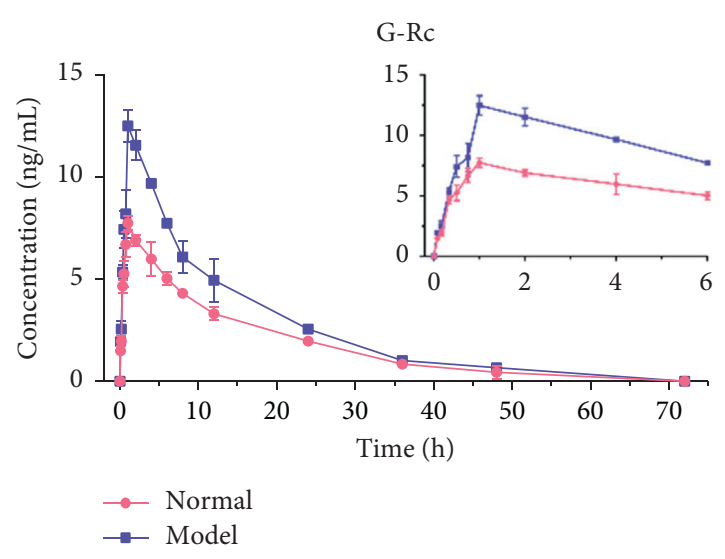

(c)

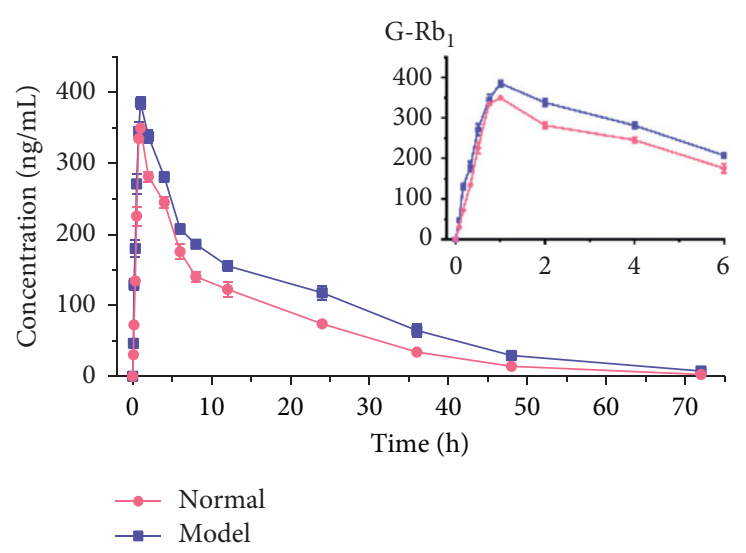

(b)

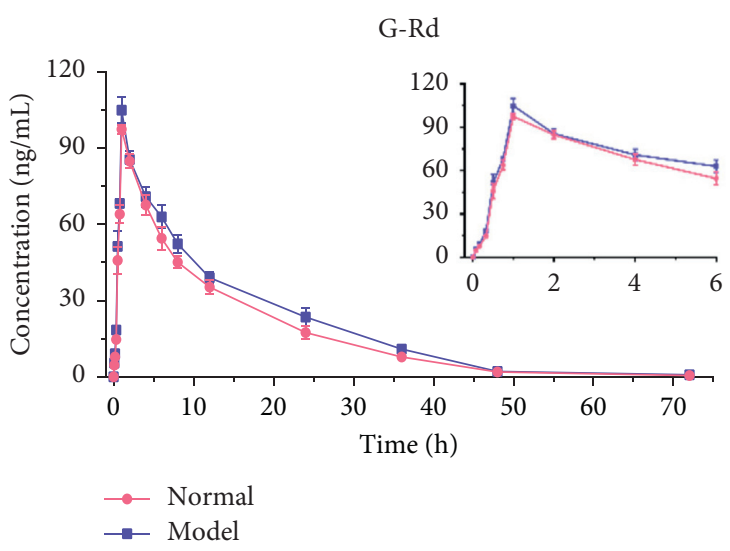

(d)

FIgURE 4: Mean plasma concentration-time profiles of compounds in rat plasma after oral administration of $G-R h_{1}(a), G-R b_{1}(b), G-R c$ (c), and G-Rd (d) at a dose of $80 \mathrm{mg} / \mathrm{kg}($ mean $\pm \mathrm{SD}, n=6)$.

\section{Conclusions}

To sum up, a new rapid UHPLC-MS/MS method was set for simultaneous determination of ginsenosides in rat plasma after oral administration in this study. The developed method was successfully applied to compare the pharmacokinetic behaviors between normal and depression model group of rats after oral administration of $\mathrm{G}-\mathrm{Rh}_{1}, \mathrm{G}-\mathrm{Rb}_{1}, \mathrm{G}-\mathrm{Rc}$, and G-Rd solutions. According to the results of this experiment, the absorption of the four ginsenosides in the normal group was not as good as that in the depression model group. It was speculated that the pathological status may affect the pharmacokinetic characteristics of rats in vivo. This method has been successfully applied to the pharmacokinetic study of ginsenosides with good specificity, precision, accuracy, recovery, and stability, which can provide new ideas and methods for the pharmacokinetic study of ginsenosides in vivo in the future.

\section{Data Availability}

The data used to support the findings of this study are included within the article.

\section{Conflicts of Interest}

The authors declare no conflicts of interest.

\section{Acknowledgments}

This research work was supported by a grant from the National Natural Science Foundation of China (No. 82073969), Jilin Province Science and Technology Development Plan Project (Nos. 20200404042YY, 20190304099YY, 20190201297JC, and 20200504003YY), and the National key Research and Development projects (No. 2019YFC1710704).

\section{References}

[1] B. Bortolato, A. F. Carvalho, J. K. Soczynska, G. I. Perini, and R. S. McIntyre, "The involvement of TNF- $\alpha$ in cognitive dysfunction associated with major depressive disorder: an opportunity for domain specific treatments," Current Neuropharmacology, vol. 13, no. 5, pp. 558-576, 2015.

[2] J. Keller, R. Gomez, G. Williams et al., "HPA axis in major depression: cortisol, clinical symptomatology and genetic variation predict cognition," Molecular Psychiatry, vol. 22, no. 4, pp. 527-536, 2017.

[3] C. F. Sharpley, V. Bitsika, N. M. Andronicos, and L. L. Agnew, "Further evidence of HPA-axis dysregulation and its correlation with depression in Autism Spectrum Disorders: data from girls," Physiology \& Behavior, vol. 167, pp. 110-117, 2016.

[4] A. Hooper, R. Paracha, and J. Maguire, "Seizure-induced activation of the HPA axis increases seizure frequency and 
comorbid depression-like behaviors," Epilepsy and Behavior, vol. 78, pp. 124-133, 2018.

[5] P. Czarny, P. Wigner, P. Galecki, and T. Sliwinski, "The interplay between inflammation, oxidative stress, DNA damage, DNA repair and mitochondrial dysfunction in depression," Progress in Neuro-Psychopharmacology and Biological Psychiatry, vol. 80, pp. 309-321, 2018.

[6] C. Skobowiat and A. T. Slominski, "UVB activates hypothalamic-pituitary-adrenal axis in C57BL/6 mice," Journal of Investigative Dermatology, vol. 135, no. 6, pp. 1638-1648, 2015.

[7] M. Han, J. J. Ban, J. S. Bae, C. Y Shin, D. H Lee, and J. H Chung, "UV irradiation to mouse skin decreases hippocampal neurogenesis and synaptic protein expression via HPA axis activation," Scientific Reports, vol. 7, no. 1, Article ID 15574, 2017.

[8] Y. Li, J. Yan, X. Zhu et al., "Dilated Virchow-Robin spaces in the hippocampus impact behaviors and effects of anti-depressant treatment in model of depressed rats," Journal of Affective Disorders, vol. 219, pp. 17-24, 2017.

[9] G. Gründer, T. Veselinović, and M. Paulzen, "Antidepressiva und Suizidalität," Nervenarzt, Der, vol. 85, no. 9, pp. 1108-1116, 2014.

[10] D. Healy, J. Le Noury, and D. Mangin, "Enduring sexual dysfunction after treatment with antidepressants, $5 \alpha$-reductase inhibitors and isotretinoin: 300 cases," The International Journal of Risk \& Safety in Medicine, vol. 29, no. 3-4, pp. 125-134, 2018.

[11] I. Y. Park, E. J. Kim, H. Park, K. Fields, A. K. Dunker, and C. Kang, "Interaction between cardiac calsequestrin and drugs with known cardiotoxicity," Molecular Pharmacology, vol. 67, no. 1, pp. 97-104, 2005.

[12] Q. Xie, K. M. Yang, G. E. Heo, and M. Song, "Literature based discovery of alternative TCM medicine for adverse reactions to depression drugs," BMC Bioinformatics, vol. 21, no. S5, pp. 405-423, 2020.

[13] W. Ru, D. Wang, Y. Xu et al., "Chemical constituents and bioactivities of Panax ginseng (C. A. Mey.)," Drug Discoveries \& Therapeutics, vol. 9, no. 1, pp. 23-32, 2015.

[14] C. H. Lee and J.-H. Kim, "A review on the medicinal potentials of ginseng and ginsenosides on cardiovascular diseases," Journal of Ginseng Research, vol. 38, no. 3, pp. 161-166, 2014.

[15] N. Yang, G. Liang, J. Lin et al., "Ginsenoside Rd therapy improves histological and functional recovery in a rat model of inflammatory bowel disease," Phytotherapy Research, vol. 34, no. 11, pp. 3019-3028, 2020.

[16] X. Li, S. Chu, M. Lin et al., "Anticancer property of ginsenoside Rh2 from ginseng," European Journal of Medicinal Chemistry, vol. 203, pp. 112627-112713, 2020.

[17] D.-S. Im, "Pro-resolving effect of ginsenosides as an antiinflammatory mechanism of Panax ginseng," Biomolecules, vol. 10, no. 3, pp. 444-453, 2020.

[18] Y. Jin, R. Cui, L. Zhao, J. Fan, and B. Li, "Mechanisms of Panax ginseng action as an antidepressant," Cell Proliferation, vol. 52, no. 6, Article ID e12696, 2019.

[19] W. Hou, Y. Wang, P. Zheng, and R. Cui, "Effects of ginseng on neurological disorders," Frontiers in Cellular Neuroscience, vol. 14, pp. 55-66, 2020.

[20] G.-L. Wang, Z.-M. He, H.-Y. Zhu et al., "Involvement of serotonergic, noradrenergic and dopaminergic systems in the antidepressant-like effect of ginsenoside $\mathrm{Rb} 1$, a major active ingredient of Panax ginseng C.A. Meyer," Journal of Ethnopharmacology, vol. 204, pp. 118-124, 2017.
[21] C. Xu, J. Teng, W. Chen et al., "20(S)-protopanaxadiol, an active ginseng metabolite, exhibits strong antidepressant-like effects in animal tests," Progress in Neuro-Psychopharmacology and Biological Psychiatry, vol. 34, no. 8, pp. 1402-1411, 2010.

[22] Y.-Z. Wang, J. Chen, S.-F. Chu et al., "Improvement of memory in mice and increase of hippocampal excitability in rats by ginsenoside Rg1's metabolites ginsenoside Rh1 and protopanaxatriol," Journal of Pharmacological Sciences, vol. 109, no. 4, pp. 504-510, 2009.

[23] S.-K. Han, M.-K. Joo, J.-K. Kim, W. Jeung, H. Kang, and D.-H. Kim, "Bifidobacteria-Fermented red ginseng and its constituents ginsenoside $\mathrm{Rd}$ and protopanaxatriol alleviate anxiety/depression in mice by the amelioration of gut dysbiosis," Nutrients, vol. 12, no. 4, pp. 901-915, 2020.

[24] N. Yamada, H. Araki, and H. Yoshimura, "Identification of antidepressant-like ingredients in ginseng root (Panax ginseng C.A. Meyer) using a menopausal depressive-like state in female mice: participation of 5-HT2A receptors," Psychopharmacology, vol. 216, no. 4, pp. 589-599, 2011.

[25] H. Zhou, H. Zhang, J. Cui et al., "Protopanaxadiol saponins in the caudexes and leaves of panax notoginseng could be the main constituents that contribute to its antidepressant effects," International Journal of Pharmacy and Pharmaceutical Sciences, vol. 6, no. 11, pp. 301-311, 2014.

[26] Q. Ye, P. Cheng, D. Yan et al., "Nine absorbed components pharmacokinetic of raw and processed Moutan Cortex in normal and blood-heat and hemorrhage syndrome model rats," Biomedical Chromatography: Biomedical Chromatography, vol. 34, no. 12, Article ID e4963, 2020.

[27] M. W. Dong and K. Zhang, "Ultra-high-pressure liquid chromatography (UHPLC) in method development," TRAC Trends in Analytical Chemistry, vol. 63, pp. 21-30, 2014.

[28] M. Lv, J. Li, X. Gao, Y. Hao, and F. Zhao, "Decreased expression of microRNA-17 in hippocampal tissues and blood from mice with depression up-regulates the expression of PAI-1 mRNA and protein," Brazilian journal of medical and biological research $=$ Revista brasileira de pesquisas medicas $e$ biologicas, vol. 53, no. 10, Article ID e8826, 2020.

[29] T. Chen, M. Zheng, Y. Li, S. Liu, and L. He, "The role of CCR5 in the protective effect of Esculin on lipopolysaccharide-induced depressive symptom in mice," Journal of Affective Disorders, vol. 277, pp. 755-764, 2020.

[30] E. P. Wang, L. Y. Du, S. Zhu et al., "Investigation of pharmacokinetic behavior of depression rats caused by UVB radiation after oral administration of 20(S)-ginsenoside Rg3 was analyzed by ultra high performance liquid chromatographytandem mass spectrom," Chinese Journal of Analytical Chemistry, vol. 49, no. 4, pp. 618-627, 2021.

[31] X. Huang, X. Liu, and Y. Yu, "Depression and chronic liver diseases: are there shared underlying mechanisms?" Frontiers in Molecular Neuroscience, vol. 10, p. 134, 2017.

[32] B.-M. Kim, J.-S. Rhee, K.-W. Lee et al., "UV-B radiationinduced oxidative stress and p38 signaling pathway involvement in the benthic copepod Tigriopus japonicus," Comparative Biochemistry and Physiology-Part C: Toxicology \& Pharmacology, vol. 167, pp. 15-23, 2015.

[33] A. Rajnochová Svobodová, A. Galandáková, J. Šianská, D. Doležal, J. Ulrichová, and J. Vostálová, “Acute exposure to solar simulated ultraviolet radiation affects oxidative stressrelated biomarkers in skin, liver and blood of hairless mice," Biological and Pharmaceutical Bulletin, vol. 34, no. 4, pp. 471-479, 2011. 
[34] K. Hodgson, K. Tansey, M. Z. Hauser et al., "Genetic differences in cytochrome P450 enzymes and antidepressant treatment response," Journal of Psychopharmacology, vol. 28, no. 2, pp. 133-141, 2014.

[35] J.-H. Zhang, H.-Z. Yang, H. Su et al., "Berberine and ginsenoside Rb1 ameliorate depression-like behavior in diabetic rats," The American Journal of Chinese Medicine, vol. 49, no. 5, pp. 1195-1213, 2021.

[36] S. J. Oh, K. Kim, and C. J. Lim, "Protective properties of ginsenoside $\mathrm{Rb} 1$ against UV-B radiation-induced oxidative stress in human dermal keratinocytes," Pharmazie, vol. 70, no. 6, pp. 381-387, 2015.

[37] Y. Oh, H.-W. Lim, K. H. Park et al., "Ginsenoside Rc protects against UVB-induced photooxidative damage in epidermal keratinocytes," Molecular Medicine Reports, vol. 16, no. 3, pp. 2907-2914, 2017.

[38] K. Yu, F. Chen, and C. Li, "Absorption, disposition, and pharmacokinetics of saponins from Chinese medicinal herbs: what do we know and what do we need to know more?" Current Drug Metabolism, vol. 13, no. 5, pp. 577-598, 2012. 